\title{
POTENCIAL ENERGÉTICO DA BIOMASSA E CARVÃO VEGETAL DO EPICARPO E DA TORTA DE PINHÃO MANSO (Jatropha curcas)
}

\author{
Ailton Teixeira do Vale", Rejane Marques Mendes², Marcela Regina Siqueira Amorim², \\ Vandui Francisco de Siqueira Dantas ${ }^{3}$
}

(recebido: 15 de abril de 2010; aceito: 29 de março de 2011)

\begin{abstract}
RESUMO: Na produção de biodiesel a partir de pinhão manso (Jatropha curcas), são gerados resíduos na forma de casca (epicarpo) e de torta. Uma das alternativas de uso desses resíduos é a produção de energia. Neste sentido, objetivou-se, com o presente trabalho, analisar o potencial energético da casca e da torta de J. curcas, caracterizando-os in natura e transformados em carvão vegetal. Foram avaliados o teor de umidade, de acordo com Vital (1997); a densidade do granel; a composição química imediata, segundo a norma ABNT NBR 8112/86 e o rendimento gravimétrico em carvão. O epicarpo apresentou teor de umidade de 18,9\%, densidade do granel de $100 \mathrm{~kg} / \mathrm{m}^{3}$, teor de materiais voláteis de $72,6 \%$, teor de carbono fixo de $13 \%$, teor de cinza de $14,4 \%$ e poder calorífico superior de $3.641 \mathrm{kcal} / \mathrm{kg}$. Carbonizado o epicarpo produziu 38,1\% de carvão vegetal, com $29 \%$ de material volátil, $45 \%$ de carbono fixo, $25 \%$ de cinza e poder calorífico superior de $3.954 \mathrm{kcal} / \mathrm{kg}$. A torta apresentou teor de umidade, em base seca, de $2,41 \%$, densidade do granel de $601 \mathrm{~kg} / \mathrm{m}^{3}$, teor de materiais voláteis de $77,84 \%$, teor de carbono fixo $14,21 \%$, teor de cinza de $7,95 \%$ e poder calorífico superior de $5.122 \mathrm{kcal} / \mathrm{kg}$. Com a carbonização da torta, obteve-se $32 \%$ de carvão vegetal com 18,27\% de materiais voláteis, 71,29\% de carbono fixo, 10,43\% de cinza e poder calorífico superior de $6.234 \mathrm{kcal} / \mathrm{kg}$. Os elevados teores de cinzas, tanto para a casca quanto para a torta, estão relacionados aos altos teores de constituintes minerais presentes nas suas respectivas estruturas anatômicas.
\end{abstract}

Palavras chaves: Resíduos, bioenergia, carbonização.

\section{ENERGY POTENTIAL OF BIOMASS AND CHARCOAL OF Jatropha curcas PEEL AND PIE}

\begin{abstract}
In the production of biodiesel from Jatropha curcas, are produced residues in the peel and of pie form. One alternative use of these residues is in the energy production. The present work analyzed the energy potential of the peel and the pie of Jatropha curcas in the following conditions: in natura and charcoal, determining: the moisture content (VITAL, 1997); the ash, fixed carbon and volatile matter (ABNT NBR 8112/86); the density and the gravimetric yield. The peel presented: moisture of 18,9\%; density of $100 \mathrm{~kg} / \mathrm{m} 3$; volatile matter of $72,6 \%$, fixed carbon of $13 \%$ and $14,4 \%$ of ashes and heat combustion of $3.641 \mathrm{kcal} / \mathrm{kg}$. The carbonized peel produced $38.1 \%$ of charcoal, with: $29 \%$ of volatile matter, $45 \%$ of fixed carbon and $25 \%$ of ashes; and heat combustion of $3.954 \mathrm{kcal} / \mathrm{kg}$. The pie presented: moisture of $2.41 \%, 601 \mathrm{~kg} / \mathrm{m} 3$ of density; volatile matter of $77.84 \%$, fixed carbon $14.21 \%$ and $7,95 \%$ ashes and $5.122 \mathrm{kcal} / \mathrm{kg}$ of heat combustion. In the carbonization of the pie, 32\% of charcoal was produced containing: $18.27 \%$ of volatile matter, $71.29 \%$ of fixed carbon, $10.43 \%$ of ashes and heat combustion of $6.234 \mathrm{kcal} / \mathrm{kg}$. The high ashe contents are related to the fertilization of the plant.
\end{abstract}

Key words: Residues, bioenergy, carbonization.

\section{INTRODUÇÃo}

Estima-se que o Brasil tenha mais de 200 espécies oleaginosas com potencial para a produção de biodiesel (BELTRÃO, 2006) e uma destas espécies é o pinhão manso (Jatropha curcas L.). O pinhão manso é uma planta oleaginosa da família Euphorbiacea que pode ser cultivada em solos pouco férteis e de clima desfavorável, como o Semi-Árido nordestino. Segundo Purcino e Drummond (1986), o cultivo de tal espécie é interessante nas pequenas propriedades, que fazem uso da mão-de-obra familiar disponível, além de ser uma cultura perene, segundo Peixoto (1973), que pode ser utilizada na conservação do solo.

Segundo Peixoto (1973), o fruto do pinhão manso é composto de 53 a $62 \%$ de sementes (endocarpo + albúmen) e de 38 a 47\% de epicarpo (casca). Penha et al. (2009) mencionam que as sementes dessa oleaginosa possuem um albúmen com até $60,8 \%$ de óleo. Devido às suas características, o pinhão-manso passou a ser considerado uma opção agrícola viável para a obtenção de biodiesel, pois produz, no mínimo, duas toneladas de óleo por hectare (CARNIELLI, 2003).

\footnotetext{
${ }^{1}$ Engenheiro Florestal, Professor Dr. em Energia na Agricultura - Departamento de Engenharia Florestal - Universidade de Brasília - Campus Universitário Darcy Ribeiro - Asa Norte - 70910-900 - Brasília, DF - ailton.vale@gmail.com

${ }^{2}$ Graduanda em Engenharia Florestal - Universidade de Brasília - Campus Universitário Darcy Ribeiro - Asa Norte - $70910-900$ - Brasília, DF rejanefloresta@yahoo.com.br, marcela.siqueira.amorim@gmail.com

32Zootecnista, Técnico laboratorista - Universidade de Brasília - Fazenda Água Limpa - Brasília, DF - vandui@unb.br
} 
Na produção do biodiesel a partir do pinhão-manso, com a retirada da semente, há a liberação do epicarpo, que pode ser considerado o primeiro resíduo do processo e, na sequência, com a prensagem da semente para a extração do óleo bruto, há a produção da torta, o segundo resíduo do processo.

Com o avanço das tecnologias de produção de sementes e com o grande potencial sócio-econômico em função das expectativas de sua produtividade, estima-se que a produção de sementes de pinhão manso aumentará, contribuindo também para o aumento dos resíduos produzidos.

Uma alternativa que se apresenta para a utilização da torta é a geração de energia e a quantidade de energia produzida por esses resíduos é diretamente influenciada por suas qualidades. Nesse sentido, a caracterização do epicarpo e da torta do pinhão manso para uso energético é um passo importante na sua utilização para a combustão.

O conhecimento de características da biomassa como: teor de umidade, densidade, composição química elementar (carbono, hidrogênio, oxigênio) e macromolecular (celulose, lignina, hemiceluloses, extrativos), composição imediata (carbono fixo, material volátil, cinza) são importantes para a utilização da biomassa como fonte de energia, pois influencia o seu poder calorífico.

O poder calorífico é definido como a quantidade de energia na forma de calor liberada pela combustão de uma unidade de massa (JARA, 1989). Divide-se em superior e inferior: Poder Calorífico Superior (PCS) é aquele em que a combustão se efetua a volume constante e no qual a água formada durante a combustão é condensada e o calor que é derivado desta condensação é recuperado (BRIANE; DOAT, 1985). Poder calorífico inferior (PCI) é a energia efetivamente disponível por unidade de massa de combustível após deduzir as perdas com a evaporação de água (JARA, 1989).

Diante do exposto, objetivou-se, com a presente pesquisa, analisar o potencial energético do epicarpo e da torta de pinhão manso "in natura" e transformado em carvão vegetal, bem como a caracterização física e energética dos referidos resíduos.

\section{MATERIAL E MÉTODOS}

\subsection{Preparação do material}

O epicarpo e a torta da semente foram fornecidos por uma empresa do interior de São Paulo, que realiza a extração do óleo de pinhão-manso. As carbonizações e a análise imediata foram realizadas na Universidade de Brasília e os ensaios de poder calorífico superior foram realizados no Serviço Florestal Brasileiro.

A fim de homogeneizar o material, os resíduos foram misturados e, posteriormente, divididos, cada um, em cinco amostras para carbonização e caracterização. A análise química imediata e a determinação do poder calorífico foram realizadas para as amostras in natura e carbonizadas. Para tanto, todas as amostras foram trituradas, classificadas em frações intermediárias, entre 40 e 60 mesh para a análise química imediata e abaixo de 60 mesh para a determinação do poder calorífico superior (PCS).

\subsection{Teor de umidade}

A determinação da umidade foi realizada com as amostras nas condições em que chegaram ao laboratório, com base na metodologia proposta por Vital (1997).

\subsection{Carbonizações}

Cinco carbonizações foram realizadas com os resíduos in natura utilizando-se uma mufla modelo Quimis, regulada à temperatura máxima de $450 \pm 10^{\circ} \mathrm{C}$, durante 3,5 horas. Amostras de $0,5 \mathrm{~kg}$ foram colocadas dentro de um cadinho metálico e este, por sua vez, foi acondicionado dentro da mufla e acoplado a uma chaminé através de um orifício circular existente na parte posterior da mesma. Após cada carbonização, o carvão foi pesado para determinação do rendimento gravimétrico em carvão vegetal, com base na massa seca da amostra.

\subsection{Análise imediata e poder calorífico}

Para a determinação do poder calorífico superior e da análise imediata da casca e da torta do pinhão manso, in natura e carbonizadas, amostras foram trituradas e classificadas em peneiras, com malhas de 40 e 60 mesh. A fração entre 40 e 60 mesh foi utilizada para a análise imediata, segundo a norma ABNT NBR 8112/86 (ASSOCIAÇÃO BRASILEIRA DE NORMAS TÉCNICAS - ABNT, 1986). O poder calorífico superior foi determinado a partir de uma amostra composta, em frações abaixo de 60 mesh, com base na norma NBR 8633 da ABNT/1984 (ABNT, 1984), usando a bomba calorimétrica PARR 1201 e como unidade calorimétrica a cal/g. 
Para o cálculo do Poder Calorífico Útil (na umidade atual) foi utilizada a seguinte expressão:

$$
\mathrm{PCU}=[\mathrm{PCI} \times(1-\mathrm{U})]-600 \mathrm{U}
$$

onde:

PCU = Poder Calorífico Útil (cal/g);

$\mathrm{U}=$ umidade em base úmida (\%);

$\mathrm{PCI}=$ poder calorífico inferior a $0 \%$ de umidade $(\mathrm{PCI}=$ PCS - 324).

\subsection{Análise estatística}

Para as análises imediatas dos resíduos in natura e os rendimentos gravimétricos de carvão vegetal e carbono fixo foi feita uma análise de variância ao nível de 5\% de probabilidade, considerando dois tratamentos: torta e epicarpo na condição in natura e transformada em carvão vegetal.

\section{RESULTADOS E DISCUSSÃO}

3.1 Características dos resíduos e rendimentos da carbonização

Na Tabela 1 são apresentados os valores médios da umidade $_{(\mathrm{bs})}$, densidade do granel, em $\mathrm{kg} / \mathrm{cm}^{3}$, e rendimento gravimétrico em carvão $(\%)$ do epicarpo e da torta do pinhão.

Tabela 1 - Valores médios da umidade ${ }_{(b s)}$, densidade do granel, em $\mathrm{kg} / \mathrm{cm}^{3}$, e rendimento gravimétrico em carvão ${ }_{(\%)}$ dos resíduos de Jatropha curcas.

Table 1 - Average values of moisture, density and gravimetric yield in charcoal of residues of Jatropha curcas.

\begin{tabular}{|c|c|c|c|c|}
\hline \multirow{3}{*}{ Variáteis } & \multicolumn{4}{|c|}{ Resíduo } \\
\hline & \multicolumn{2}{|c|}{ Epicarpo } & \multicolumn{2}{|c|}{ Torta } \\
\hline & In natura & carvão & In natura & carvão \\
\hline Umidade** (\%) & $\begin{array}{c}18,9 \\
(8,07)\end{array}$ & $0 *$ & $\begin{array}{c}2,41 \\
(13,69)\end{array}$ & $0 *$ \\
\hline $\begin{array}{l}\text { Densidade do } \\
\text { granel }\left(\mathrm{kg} / \mathrm{m}^{3}\right)\end{array}$ & $\begin{array}{l}100,6 \\
(3,23)\end{array}$ & - & $\begin{array}{c}601 \\
(3,85)\end{array}$ & - \\
\hline $\begin{array}{l}\text { Rendimento em } \\
\text { carvão** (\%) }\end{array}$ & - & $\begin{array}{c}38,1 \\
(2,22)\end{array}$ & & $\begin{array}{l}32,01 \\
(1,35)\end{array}$ \\
\hline
\end{tabular}

Obs.: *na saída do forno. **em base seca. Os valores entre parênteses correspondem aos coeficientes de variação, em \%.

A umidade do resíduo armazenado varia, dentre outros fatores, com a geometria das partículas, densidade do granel, tempo e condições do local de armazenamento (principalmente umidade relativa do ar e temperatura) e tende, com o transcorrer do tempo, a estabelecer um equilíbrio com o meio. Farinhaque (1981), em um estudo sobre a influência da umidade no poder calorífico da madeira de bracatinga, afirma que na combustão o teor de umidade não deve estar acima de $25 \%$ de umidade, pois umidades elevadas reduzem o valor do calor de combustão, a temperatura da câmara de queima e a temperatura dos gases de escape. Isso pode ser extrapolado para os resíduos de biomassa em geral, e, neste sentido, com umidades abaixo de $25 \%$, o epicarpo e a torta de pinhão manso estariam dentro do esperado para a combustão em equipamentos apropriados. A torta de pinhão manso, um resíduo mais compacto que o epicarpo, apresentou teor de umidade muito baixo (2,41\%), provavelmente como efeito da prensagem da amêndoa. Vale et al. (2007), trabalhando com resíduos de café e de madeira, encontraram umidade de $13,5 \%$ para a casca de café (Coffea arabica, $L$ ) e de $17,1 \%$ para os resíduos de madeira (Cedrelinga catenaeformis).

O teor de umidade é um fator de grande importância no uso da biomassa como combustível, pois apresenta uma relação inversa com o poder calorífico; prejudica o armazenamento, uma vez que pode ocasionar a proliferação de fungos e a degradação do material; além de elevar os custos de transporte.

O epicarpo do pinhão manso apresentou rendimento gravimétrico médio em carvão de 38,1\%, significativamente diferente, ao nível de 5\% de probabilidade (Tabela 3), da torta que apresentou um rendimento médio de 32,01\%, portanto em torno de $19 \%$ a menos de carvão. Vale et al. (2004), trabalhando com carvão vegetal de coco-da-baía (Cocos nucifera L.), encontraram um valor semelhante (39,6\%), para a casca do coco verde, quando houve a carbonização de todo o fruto e para o coco maduro $(36,1 \%)$, quando foi utilizado apenas o endocarpo na carbonização.

De acordo com Vale et al. (2007), o epicarpo do pinhão manso com densidade do granel igual a $100 \mathrm{~kg} / \mathrm{m}^{3}$ pode ser considerado um resíduo leve quando comparado com a casca de café $\left(167 \mathrm{~kg} / \mathrm{m}^{3}\right)$ e com resíduos de madeira $\left(115 \mathrm{~kg} / \mathrm{m}^{3}\right)$. Com uma menor granulometria média, a torta apresentou densidade do granel de $601 \mathrm{~kg} / \mathrm{m}^{3}$. No entanto, vale registrar que, da prensagem da amêndoa até utilização final, a granulometria média da torta diminui em função do manuseio. Em geral, quanto menor a granulometria média do material, maior será a densidade do granel, pois há uma maior compactação das partículas no recipiente em que a densidade está sendo determinada. 
Dessa forma, os valores baixos encontrados, principalmente para as amostras de epicarpo de pinhão manso, podem implicar maiores custos de transporte e dificuldades no manejo do resíduo, caso não seja feita uma compactação.

\subsection{Análise imediata}

Observa-se, na Tabela 2, teor médio de materiais voláteis no epicarpo de $72,6 \%$ e da torta de $77,4 \%$ in natura, estando dentro da faixa esperada que é de 65 a 83\% (CORTEZ; LORA, 1997) e teores de material volátil de 29,0\% para o carvão de epicarpo e 18,27\% para o carvão de torta, valores semelhantes à média de 18\% observada por Andrade et al. (2004) para Eucalyptus urophylla.

Com exceção do teor de carbono fixo do resíduo in natura, todas as demais variáveis, incluindo o rendimento gravimétrico da Tabela 1, apresentaram diferenças significativas entre os tratamentos ao nível de 5\% de probabilidade, conforme Tabela 3.

Os teores de cinza acima de 7\% são considerados elevados, tanto para o epicarpo quanto para a torta, nas condições in natura e carvão. O teor de cinza está relacionado com a presença de minerais provenientes, em parte, da adubação química como cálcio, potássio, fósforo, magnésio, ferro, sódio, entre outros. Tienne et al. (2004), ao carbonizarem casca de laranja e casca com bagaço de laranja, associaram os altos valores de cinza encontrados (9,5 e 10,25\%, respectivamente) à presença de ferro, zinco, cobre, potássio, cálcio, fósforo, sódio e magnésio. Oliveira Júnior et al. (2007), analisando a composição da casca (epicarpo) e da torta, afirmaram que a análise mostrou consideráveis teores de cálcio, potássio, fósforo, ferro, manganês, sódio, magnésio, nitrogênio, enxofre, boro, zinco e cobre; apresentando um elevado teor de potássio na casca de 60,2 g. $\mathrm{kg}^{-1}$ e de teor de nitrogênio de 34,6 g. $\mathrm{kg}^{-1}$ na torta, além de um elevado teor de cinza em ambos (15,9\% e 7,4\% na torta e na casca, respectivamente). Trabalho conduzido no Centro Tecnológico de Minas Gerais - CETEC (1983) - apresentou um teor de cinza na semente de pinhão manso (endocarpo + albúmen) que, após a prensagem, se transforma em torta, de $7,36 \%$.

Tabela 2 - Valores médios de material volátil, cinzas e carbono fixo de biomassa e carvão vegetal de resíduos de Jatropha curcas.

Table 2 - Average values of volatile matter, ash content and fixed carbon of biomass and charcoal of residues of Jatropha curcas.

\begin{tabular}{lcccc}
\hline \multirow{2}{*}{ Variáveis } & \multicolumn{3}{c}{ Resíduos } \\
\cline { 2 - 5 } & \multicolumn{2}{c}{ Epicarpo } & \multicolumn{2}{c}{ Torta } \\
\cline { 2 - 5 } & In natura & carvão & In natura* & carvão \\
\hline Material volátil (MV) (\%) & $72,6(2,15)$ & $29,0(16,6)$ & $77,4(1,03)$ & $18,27(9,49)$ \\
Cinzas (CZ) (\%) & $14,43(10,4)$ & $25,5(10,45)$ & $7,95(7,00)$ & $10,43(8,09)$ \\
Carbono fixo (CF) (\%) & $13,0(9,91)$ & $45,5(16,09)$ & $14,21(9,28)$ & $71,29(2,17)$ \\
Rendimento carbono fixo (RCF) (\%) & - & $17,42(16,29)$ & - & $22,82(2,64)$ \\
\hline
\end{tabular}

*Endocarpo + albúmen. Os valores entre parênteses correspondem aos coeficientes de variação, em \%.

Tabela 3 - Valores de "F” para material volátil, cinzas e carbono fixo de biomassa; material volátil, cinzas, carbono fixo de carvão; rendimento gravimétrico em carvão e rendimento gravimétrico em carbono fixo de resíduos de Jatropha curcas.

Table 3 - Values of " $F$ " for volatile material, ash and fixed carbon from biomass; volatile material, ash, fixed carbon from charcoal; gravimetric yield in charcoal and gravimetric yield in fixed carbon of residues of Jatropha curcas.

\begin{tabular}{|c|c|c|c|c|c|c|c|c|c|}
\hline \multirow{3}{*}{ FV } & \multirow{3}{*}{ GL } & \multicolumn{8}{|c|}{ Valores de "F" } \\
\hline & & \multicolumn{3}{|c|}{ in natura } & \multicolumn{5}{|c|}{ Carvão vegetal } \\
\hline & & MV & $\mathrm{CZ}$ & $\mathrm{CF}$ & MV & $\mathrm{CZ}$ & $\mathrm{CF}$ & $\mathrm{Rg}$ & RCF \\
\hline Tratamento & 1 & & & & & & & & \\
\hline Resíduo & 8 & $44,90 *$ & $81,31^{*}$ & $1,18^{\mathrm{ns}}$ & $21,73^{*}$ & $145,04 *$ & $59,13 *$ & 203,88* & $18,10^{*}$ \\
\hline Total & 9 & & & & & & & & \\
\hline
\end{tabular}

Cerne, Lavras, v. 17, n. 2, p. 267-273, abr./jun. 2011 
Combustíveis com alto índice de carbono fixo apresentam queima mais lenta, implicando maior tempo de residência nos aparelhos de queima, em comparação com outros que tenham menor teor de carbono fixo (BRITO; BARRICHELLO, 1982). Neste caso, para o uso in natura, a torta leva uma ligeira vantagem em relação ao epicarpo, mas observa-se um maior teor de material volátil para a torta, além de um menor teor de cinza.

O rendimento em carbono fixo é o produto do rendimento gravimétrico em carvão vegetal e do teor de carbono fixo. Neste sentido, através da observação simultânea das Tabelas 1 e 2, nota-se que, mesmo com um maior rendimento em carvão vegetal, a carbonização da casca resultou em um menor rendimento em carbono fixo, devido aos elevados teores de cinza e de materiais voláteis no carvão. Na prática, isso quer dizer que, em base seca, para cada $100 \mathrm{~kg}$ de carbono fixado na massa de carvão vegetal, necessita-se carbonizar 574kg de epicarpo ou 438kg de torta. Ou ainda: a carbonização de 100 kg a.s. de epicarpo ou de torta, fornecerá, respectivamente, 17,42 $\mathrm{kg}$ e $22,82 \mathrm{~kg}$ de carbono.

\subsection{Poder calorífico}

Na Tabela 4, encontram-se os resultados do poder calorífico superior e útil para o epicarpo e a torta do pinhão manso in natura e transformados em carvão vegetal.

Tabela 4 - Valores médios de poder calorífico de biomassa e carvão vegetal de resíduos de Jatropha curcas.

Table 4 - Average values of combustion heat of biomass and charcoal of Jatropha curcas residues.

\begin{tabular}{lcccc}
\hline \multirow{2}{*}{ Variáveis } & \multicolumn{4}{c}{ Resíduos } \\
\cline { 2 - 5 } & \multicolumn{2}{c}{ Epicarpo } & \multicolumn{2}{c}{ Torta } \\
\cline { 2 - 5 } & $\begin{array}{c}\text { In } \\
\text { natura }\end{array}$ & carvão & $\begin{array}{c}\text { In } \\
\text { natura }\end{array}$ & carvão \\
\hline $\begin{array}{l}\text { Poder calorífico } \\
\text { superior (kcal/kg) }\end{array}$ & 3.461 & 3.954 & 5.122 & 6.233 \\
$\begin{array}{l}\text { Poder calorífico } \\
\text { útil (kcal/kg) }\end{array}$ & 2.612 & - & 4.671 & - \\
\hline
\end{tabular}

O epicarpo apresentou menor poder calorífico em comparação à torta, devido, em parte, ao alto teor de cinza. O maior poder calorífico da torta, por sua vez, pode estar relacionado ao menor teor de cinza e à presença de um resíduo de óleo.
O poder calorífico útil é, como esperado, menor que o poder calorífico superior, pois este último contabiliza o calor derivado da condensação de água. Portanto, em termos reais, a quantidade de energia na forma de calor liberada pela combustão do epicarpo e da torta foi de, respectivamente, $2.612 \mathrm{kcal} / \mathrm{kg}$ e 4.671 $\mathrm{kcal} / \mathrm{kg}$.

Com base nos dados da REDENERGIA (2010), o poder calorífico superior do epicarpo do pinhão manso é maior que o da casca de semente de algodão (2.800kcal/ $\mathrm{kg}$ ou $11,70 \mathrm{Mj} / \mathrm{kg}$ ), sabugo de milho (2.900kcal $/ \mathrm{kg}$ ou $12,12 \mathrm{Mj} / \mathrm{kg}$ ) e menor que o da borra de café $(5.500 \mathrm{kcal} /$ $\mathrm{kg}$ ou 22,99 Mj/kg) e casca de coco de babaçu (4.500kcal/ $\mathrm{kg}$ ou $18,81 \mathrm{Mj} / \mathrm{kg}$ ). Também é menor que o poder calorífico médio do coco-da-baía verde (Cocos nucifera) de $5.636 \mathrm{kcal} / \mathrm{kg}$ ou 23,55 Mj/kg, segundo Vale et al. (2004).

Segundo a REDENERGIA (2010), o poder calorífico superior da torta in natura é maior que o da casca de semente de algodão (2.800 kcal/kg), palha de arroz (3.500 kcal/kg), sabugo de milho (2.900 kcal/kg) e casca de coco de babaçu (4.500 kcal/kg), sendo menor que o da borra de café (5.500 kcal/kg). De acordo com Quirino et al. (2005), também é maior que o poder calorífico superior do bagaço-de-cana (3.700 kcal/kg).

Com o poder calorífico médio de $5.122 \mathrm{kcal} / \mathrm{kg}$, a torta de pinhão manso composta de endocarpo (casca) e albúmen, supera o poder calorífico superior apresentado pela madeira de Eucalyptus grandis, de $4.790 \mathrm{kcal} / \mathrm{kg}$ (JARA, 1989).

\subsection{Discussão final}

Segundo Arruda et al. (2004), a torta é utilizada como fertilizante natural, em virtude do seu elevado teor de nitrogênio, fósforo e potássio. Oliveira Júnior et al. (2007) defendem, além da torta, o uso da casca também como fertilizante, para ciclagem de nutrientes, uma vez que apresentam uma elevada quantidade de potássio (casca) e nitrogênio (torta). Por outro lado, Biodiesel-BR (2008) menciona que a utilização do epicarpo pode vir a atender a geração de vapor nas caldeiras e, consequentemente, à necessidade energética na fase industrial de processamento das sementes.

São fornecidos, neste trabalho, alguns dados que poderão ser úteis na decisão de uso desses resíduos, mas uma variável importante nesta decisão é o custo do transporte do resíduo, caso ele seja produzido a grandes distâncias do centro de consumo.

Cerne, Lavras, v. 17, n. 2, p. 267-273, abr./jun. 2011 
O epicarpo pode ser utilizado como combustível, no entanto, apresenta características energéticas desfavoráveis, quando comparado com biomassas tradicionais como a madeira. No caso do epicarpo, destaca-se a baixa densidade do granel $\left(100,6 \mathrm{~kg} / \mathrm{m}^{3}\right)$ que, associada ao baixo poder calorífico útil $(2.612 \mathrm{kcal} / \mathrm{kg})$, produz uma baixa densidade energética $\left(\mathrm{kcal} / \mathrm{m}^{3}\right)$ e um elevado teor de cinza (14,4\%).

Se o epicarpo é produzido muito distante do centro consumidor e a decisão for pelo uso energético, sugere-se, para contornar o problema da baixa densidade energética, a briquetagem ou adensamento que, além de homogeneizar o material, facilita o seu transporte e alimentação na caldeira.

O alto teor de cinza do epicarpo $(14,4 \%)$ implica duas questões que devem ser equacionadas: o maior cuidado com a limpeza do aparelho de queima e a maior atenção ao estado das tubulações. Devido a alta produção de cinza, deve ser maior o cuidado com a limpeza do equipamento. $\mathrm{O}$ maior cuidado com as tubulações vincula-se ao fato de que, durante a queima do epicarpo, o seu alto teor de potássio poderá gerar incrustações nas mesmas.

A torta também pode ser utilizada para fins energéticos e, diferentemente do epicarpo, apresenta melhores características como densidade do granel de $601 \mathrm{~kg} / \mathrm{m}^{3}$ e poder calorífico útil igual a $4.671 \mathrm{kcal} / \mathrm{kg}$, com uma elevada densidade energética, apesar de apresentar um alto teor de cinza (7,95\%). A sugestão de briquetagem ou adensamento também pode ser proposta para a torta, melhorando ainda mais a sua densidade energética.

Com rendimentos gravimétricos em carvão vegetal de $38,1 \%$ para a casca e $32 \%$ para a torta, ambos os resíduos podem ser utilizados para a carbonização. A torta leva vantagem em relação ao epicarpo por apresentar um maior rendimento em carbono fixo e um maior poder calorífico.

\section{CONCLUSÕES}

De acordo com os resultados das avaliações realizadas, a torta de pinhão-manso "in natura” e transformada em carvão vegetal possui potencial para ser usada com finalidades energéticas. Tal resíduo apresenta características favoráveis para este fim, sendo algumas delas, inclusive, semelhantes às apresentadas pela madeira de eucalipto. No entanto, deve-se atentar para o elevado teor de cinza da torta, que é, aproximadamente, 7 vezes maior do que o apresentado pela madeira.

Cerne, Lavras, v. 17, n. 2, p. 267-273, abr./jun. 2011
O epicarpo de pinhão manso também pode ser utilizado para fins energéticos. No entanto, apresenta características inferiores à torta e, consequentemente, à madeira. Quando comparado com a madeira de eucalipto, o teor médio de cinza do epicarpo pode ser 14 vezes maior, o que induz à utilização de sistemas mais eficientes entre outros cuidados.

\section{REFERÊNCIAS}

ANDRADE, A. M. de; PASSOS, P. R. de A.; MARQUES, L. G. da C.; OLIVEIRA, L. B.; VIDAURRE, G. B.; ROCHA, J. das D. de S. Pirólise de resíduos do Coco-da-Baía (Cocos nucifera L.) e análise do carvão vegetal. Revista Árvore, Viçosa, v. 28, n. 5, p. 707-714, 2004.

ARRUDA, F. P. de; BELTRÃO, N. E. de M.; ANDRADE, A. P. de; PEREIRA, W. E.; SEVERINO, L. S. Cultivo de Pinhão Manso (Jatropha curcas L.) como alternativa para o Semi-Árido Nordestino. Revista Brasileira de Oleaginosas e Fibrosas, Campina Grande, v. 8, n. 1, p. 789-799, jan./abr. 2004.

ASSOCIAÇÃO BRASILEIRA DE NORMAS TÉCNICAS. NBR 8112: análise imediata. Rio de Janeiro, 1986.

\section{ASSOCIAÇÃO BRASILEIRA DE NORMAS TÉCNICAS.}

NBR 8633: determinação do poder calorífico superior. Rio de Janeiro, 1984.

BELTRÃO, N. E. M. Considerações gerais sobre o pinhão manso (Jatropha curcas L.). Campina Grande: RBB, 2006. Disponível em: <http://www.rbb.ba.gov.br/arquivo/384.pdf> . Acesso em: 10 ago. 2008.

BIODIESELBR. Pinhão manso. Disponível em: <http:// www.pinhaomanso.com.br/tudo-sobre-pinhao-mansojatrophacurcas.html>. Acesso em: 10 dez. 2008.

BRIANE, D.; DOAT, J. Guide technique de la carbonisation: la fabrication du charbon de bois. AixenProvence: ÉDISUD, 1985. 180 p.

BRITO, J. O.; BARRICHELO, L. E. G. Carvão vegetal de madeira de desbaste de Pinus. Circular Técnica IPEF, Piracicaba, v. 146, p. 1-12, jun. 1982.

CARNIELLI, F. O combustível do futuro. Boletim UFMG, Belo Horizonte, ano 29, n. 1413, 2003. Disponível em: <http://www. ufmg.br/boletim/bol1413/quarta.shtml>. Acesso em: 12 mar. 2009. 
CENTRO TECNOLÓGICO DE MINAS GERAIS. Produção de combustíveis líquidos a partir de óleosvegetais: relatório final do convênio STI- MIC/CETEC. Belo Horizonte, 1983. 2 v.

CORTEZ, L. A. B.; LORA, E. S. Tecnologia de conversão energética da biomassa. Manaus: Universidade do Amazonas, 1997. 19 p.

FARINHAQUE, R. Influência da umidade no poder calorífico da madeira de bracatinga (Mimosa scabrella, Benth), e aspectos gerais de combustão. Curitiba: FUPEF, 1981. 13 p. (Série técnica, 6).

JARA, E. R. P. O poder calorífico de algumas madeiras que ocorrem no Brasil. São Paulo: Instituto de Pesquisas Tecnológicas, 1989. (Comunicação técnica, 1797).

OLIVEIRA JÚNIOR, J. B.; MARCELA, D. N.; FRAGA, A. C.; CASTRO NETO, P. Determinação dos nutrientes presentes na casca e torta de pinhão-manso. In: CONGRESSO BRASILEIRO DE PLANTAS OLEAGINOSAS, ÓLEOS, GORDURAS E BIODIESEL, 4., 2007, Varginha. Anais... Varginha, 2007. p. 1763-1770.

PEIXOTO, A. R. Plantas oleaginosas arbóreas. São Paulo: Nobel, 1973. 284 p.

PENHA, M. da N. C.; MACIEL, A. P.; MENDONÇA, K. K. M.; FERREIRA, A. M.; MOUCHREK FILHO, V. E.; SILVA, M. D. P.; SILVA, F. C. Características físico-químicas do pinhão manso (Jatropha curcas L.) cultivado no Maranhão. Brasília: Embrapa Agrobioenergia, 2009. Disponível em: <http://www.cpamn.embrapa.br/agrobioenergia/trabalhos/146. PDF $>$. Acesso em: 10 fev. 2009.
PURCINO, A. A. C.; DRUMMOND, A. O. Pinhão manso. Belo Horizonte: Epamig, 1986. 7 p.

QUIRINO, W. F.; VALE, A. T. do; ANDRADE, A. P. A. de; ABREU, V. L. S.; AZEVEDO, A. C. dos S. Poder calorífico da madeira e de materiais lignocelulósicos. Revista da Madeira, São Paulo, n. 89, p. 100-106, 2005.

REDENERGIA. Poderes caloríficos. Disponível em: $<$ http://redenergia.com.br/infotec.asp>. Acesso em: 11 abr. 2010.

TIENNE, L.; DESCHAMPS, M. C.; ANDRADE, A. M. Produção de carvão e subprodutos da pirólise da casca e do bagaço da laranja (Citrus sinensis). Biomassa \& Energia, Viçosa, v. 1, n. 2, p. 191-197, 2004.

VALE, A. T.; BARROSO, R. A.; QUIRINO, W. J.

Caracterização da biomassa e do carvão vegetal do coco-dabahia (Cocos nucefera L.). Biomassa \& Energia, Viçosa, v. 1, p. 365-370, 2004.

VALE, A. T.; GENTIL, L. V.; GONÇALEZ, J. C.; COSTA, A. F. Caracterização energética da biomassa e rendimento da carbonização de resíduos de grãos de café (Coffea arabica, L) e de madeira (Cedrorana catenaeformis), Duke. In: CONGRESSO INTERNACIONAL DE AGROENERGIA E BIOCOMBUSTÍVEIS, 2007, Teresina. Anais... Teresina, 2007. CD-ROM.

VITAL, B. R. Métodos para determinação do teor de umidade da madeira. Viçosa, MG: SIF, 1997. 33 p. (Boletim técnico SIF, 13). 